\title{
The Effectiveness Of Providing Vulanic Ash (Tuff Vulcan) And Dolomite As Amelioran Materials On The Growth Of Immature Liberica Coffee Plants In Peat Land Of Mekar Jaya Village
}

\author{
YG. Armando, Anis Tatik Maryani, M syarif \\ Department of Agroecotechnology, Faculty of Agriculture, Jambi University \\ Email corresponding authors: yunta gombang@gmail.com
}

\begin{abstract}
Liberika coffee is one type of coffee that is widely cultivated by people in wetland areas (peat) precisely in Betara District, Tanjung Jabung Barat Regency. In recent years, this district has become a development center and provider of Liberika coffee seeds for coffee plantation farmers from various regions such as Palembang, Kalimantan and Riau. Liberika coffee is a type of coffee that is able to adapt and produce quite well in peatlands with areca nut as a cover crop. The productivity of coffee in this area is still low at an average of $715 / \mathrm{kg}$ when compared to the potential yield of Liberika coffee which can reach $950 \mathrm{~kg} / \mathrm{ha}$. Increasing production and productivity can be done through intensification and extensification. One of the efforts to improve the physical and chemical properties of peat soils so as to increase the growth and production of coffee plants is the use of ameliorants (soil enhancers). This study aims to develop a technology for using ameliorant to improve the chemical properties of peat soil. Specifically, through this study, the dosage combination of vulcan tuff ash and dolomite can be identified. which can substitute the use of artificial fertilizers (inorganic) so that it can increase the growth and production of immature liberica coffee plants on peatlands. especially the coffee plantation of farmers in the village of mekar jaya, betara district, tanjung jabung west district. From the results of this study it can be concluded that the treatment of volcanic ash and dolomite did not show significant differences in plant height parameters and, stem diameter. but it gives a real difference to the growth of live area, the number of flowers per bunch and the number of flowers in each bunch. treatment of volcanic ash 500 / gr / tree and dolomite 500 / gr / tree and a combination of volcanic ash 250 / gr / tree + dolomite 250 / gr / tree after 7 weeks of application can significantly spur on the initiation of flowering an average of 7 bunches of branch flowers if compare with control (no treatment). Likewise, observations 8 weeks after application showed the same thing, there was an increase in the number of flowers formed an average of 11 flower clumps branching. From the results of this study, it can be concluded that the provision of ameliorant from vulcan tuff ash and dolomite can improve the chemical properties of peat soil so as to increase nutrient availability for growth and production of the Liberika coffee plant. From the
\end{abstract}


results of this study, it can also be suggested that the use of volcanic ash and dolomite at a dose of 250-500 gr / tree to accelerate the productive phase of immature liberica coffee plants (young plants) in peatlands.

Keywords: ameliorant, growth and production of Liberica coffee.

\section{PENDAHULUAN}

Tanaman kopi merupakan salah satu tanaman perkebunan yang memiliki peranan penting sebagai sumber devisa negara dan penggerak perekonomian di Indonesia. Terdapat empat jenis kopi yang telah dikenal, yaitu kopi arabika, kopi robusta, kopi liberika dan kopi ekselsa (Rahardjo, 2017). Jenis kopi arabika, robusta dan liberika merupakan jenis kopi yang umum dibudidayakan di Indonesia termasuk di Provinsi Jambi.

Kopi liberika merupakan salah satu jenis kopi yang banyak diusahakan masyarakat di daerah lahan basah (gambut) tepatnya di Kecamatan Betara Kabupaten Tanjung Jabung Barat. Kabupaten ini dalam beberapa tahun terakhir telah menjadi sentra pengembangan dan penyedia bibit kopi liberika bagi petani perkebunan kopi dari berbagai wilayah seperti Palembang, Kalimantan dan Riau.

Kopi liberika merupakan salah satu jenis kopi yang mampu beradaptasi dan berproduksi cukup baik di lahan gambut dengan tanaman pinang sebagai tanaman pelindung. (Azizah, 2017). Luas areal pertanaman kopi liberika di Tanjung Jabung Barat pada tahun 2016 mencapai 2.871 ha dengan total produksi mencapai 1.281 ton dan produktivitas $673 \mathrm{~kg} / \mathrm{ha}$. Pada tahun 2017 mencapai 2.997 ha dengan total produksi mencapai 1.411 ton dan produktivitas $715 \mathrm{~kg} / \mathrm{ha}$ (Dinas Perkebunan Provinsi Jambi, 2018), Produktivitas kopi didaerah ini masih rendah yang rata - rata 715/kg apabila dibandingkan dengan potensi hasil kopi liberika nasional yang dapat mencapai 950 $\mathrm{kg} / \mathrm{ha}$. Peningkatan produksi dan produktivitas dapat dilakukan melalui intensifikasi dan ekstensifikasi.

Salah satu upaya yang dapat dilakukan untuk peningkatan produksi dan produktivitas kopi ini adalah melalui intensifikasi dengan cara melakukan perbaikan dan pemeliharaan tanaman seperti penggunaan bibit unggul, pemupukan/perbaikan kualitas lahan, pamangkasan dan penanganan pasca panen.

Pertumbuhan tanaman pada lahan gambut dipengaruhi oleh beberapa faktor diantaranya ketersediaan unsur hara. Lahan gambut tergolong lahan marginal yang memiliki sifat fisik dan kimia tanah yang buruk dan sangat mudah mengalami kerusakan (degradasi). Ketersediaan unsur hara rendah pada tanah gambut terutama dipengaruhi oleh sifat kimia tanah. Sifat kimia tanah gambut menurut Zuraida (2013) memiliki karakteristik diantaranya $\mathrm{pH} \mathrm{H}_{2} \mathrm{O}$ 1:2,5 4,90 masam, C-Organik (\%) 46,09 
sangat tinggi, kation-kation basa: $\mathrm{K}-\mathrm{dd}\left(\mathrm{cmol} \mathrm{kg}^{-1}\right)$ 1,39 sangat tinggi, $\mathrm{Na}-\mathrm{dd}(\mathrm{cmol} \mathrm{kg}-$ 1) 1,64 sangat tinggi, Ca-dd $\left(\mathrm{cmol} \mathrm{kg}^{-1}\right) 5,50$ rendah, $\mathrm{Mg}$-dd $\left(\mathrm{cmol} \mathrm{kg}^{-1}\right)$ 1,01 rendah, KTK ( $\mathrm{cmol} \mathrm{kg}^{-1}$ ) 107,05 sangat tinggi, kejenuhan basa (\%) 17,38 sangat rendah, H-dd (cmol $\left.\mathrm{kg}^{-1}\right)$ 1,60 rendah, Al-dd $\left(\mathrm{cmol} \mathrm{kg}^{-1}\right)$ 1,40 rendah. Kandungan $\mathrm{N}$-total tinggi namun C/N yang tinggi menyebabkan $\mathrm{N}$ tidak tersedia bagi tanaman. Selain itu, kadar P dan $\mathrm{K}$ tanah gambut umumnya rendah dibanding tanah mineral sehingga tanaman pada tanah gambut memiliki respon yang baik terhadap pemupukan P dan K (Sani, 2011).

Salah satu upaya untuk memperbaiki sifat fisik dan kimia tanah gambut sehingga dapat meningkatkan pertumbuhan dan produksi tanaman kopi adalah dengan penggunaan amelioran (pembenah tanah). Amelioran merupakan bahan organik dan atau anorganik yang ditambahkan ke dalam tanah untuk memperbaiki tempat tumbuh tanaman (Maftu'ah et al., 2013). Efektivitas aplikasi bahan amelioran di lahan gambut ditentukan oleh kualitas bahan terutama komposisi kimia bahan baku diantaranya yang mengandung kation-kation basa polivalen yang mampu mengurang pengaruh toksik dari asam-asam organik.

Efektivitas amelioran dapat ditingkatkan melalui pencampuran dua atau lebih bahan amelioran. Beberapa jenis amelioran organik dan anorganik yang berpotensi diaplikasikan di lahan gambut diantaranya tuff volkan, dolomit, dan tanah mineral.

\section{METODE}

Penilitan ini adalah penelitian satu faktor dengan menggunakan Rancangan Lingkungan acak kelompok (Randomized Block Design) yaitu aplikasi abu tuff vulcan dan dolomit dengan 6 taraf perlakuan dan 3 ulangan, Adapun perlakuan penelitian adalah sebagai berikut.

$\mathrm{A}_{0}=$ Tanpa aplikasi amelioran

$\mathrm{A}_{1}=$ Dolomit $250 \mathrm{gr} /$ Pohon

$\mathrm{A}_{2}=$ Dolomit $500 \mathrm{gr} /$ Pohon

$\mathrm{A}_{3}=$ Abu vulkanik 250gr/Pohon

$\mathrm{A}_{4}=\mathrm{Abu}$ vulkanik $500 \mathrm{gr} /$ Pohon

$\mathrm{A}_{5}=\mathrm{Abu}$ vulkanik 250gr + Dolomit 250gr/Pohon

Setiap perlakuan diulang 3 kali sehingga terdapat 18 Batang percobaan.

Data hasil pengamatan yang di peroleh diuji melalui analisis ragam dan apabila perlakuan yang diuji cobakan menunjukan perbedaan yang nyata maka untuk mendapatkan perbedaan antara perlakuan dilanjutkan dengan di uji jarak berganda, ( DNMRT ).

HASIL PEMBAHASAN 


\section{Pertumbuhan Tinggi Tanaman}

Pertumbuhan tanaman merupakansuatu proses yang ditandai dengan bertambahnya ukuran dan berat tanaman. Penambahan ini di sebabkan oleh bertambahnya ukuran organ tanaman seperti tinggi tanaman, diameter, dan jumlah daun sebagai akibat dari metabolisme tanaman yang juga di pengaruhi oleh faktor lingkungan di daerah pertanaman seperti suhu, curah hujan, kelembaban, intensitas cahaya matahari, air, serta nutrisi dalam tanah. Pertumbuhan tanaman juga di pengarihi oleh faktor genetik tanaman tersebut. Tanaman juga membutuhkan unsur hara untuk melakukan prosesproses metabolisme, terutama pada masa vegetatif. Di harapkan unsur yang terserap digunakan untuk mendorong pembelahan seldan pembelahan sel-sel baru guna membentuk organ tanaman seperti daun, batang, dan akar yang lebih baik.

Berdasarkan hasil analisis tanah awal pada percobaan ini memiliki $\mathrm{pH}$ tanah di bawah optimal dengan kandungan hara N,P dan K yang tergolong rendah. Akibatnya tanah tersebut membutuhkan penambahan hara dalam tanah seperti bahan-bahan organik dari luar, agar tanah di lahan gambut dapat di perbaiki kesuburannya. Percobaan ini juga menunjukan bahwa pemberian Abu Vulkanik dan Dolomit sebagai bahan pembenah tanah dapat membantu memperbaiki sifat tanah dan memberikan kandungan unsur hara dalam tanah yang yang berguna untuk pertumbuhan kopi liberika.

Hal tersebut dapat di lihat dari hasil sidik ragam yang menunjukkan bahwa pemberian Abu Vulkanik dan Dolomit terhadap pertumbuhan kopi liberika di lahan gambut memberikan pengaruh nyata terhadap pertambahan tinggi tanaman, lebar daun, panjang daun, luas daun, diameter batang, Jumlah Dompolan Bunga Percabang Tanaman Kopi dan Jumlah Bunga Pada Setiap Dompolan Abu Vulkanil memiliki kandungan $\mathrm{N}, \mathrm{P}, \mathrm{K}$, di mana unsur $\mathrm{P}$ yang terkandung dari abu vulkanik berguna bagi tanaman untung merangsang pertumbuhan tanaman secara keseluruhan, termasuk dalam mendorong dan mempercapat tumbuh atau menanbah tinggi suatu tanaman serta mengaktifkan sifat kerja unsur lain. Bahwa kesuburan tanah secara tidak langsung berhubungan dengan komposisi kimia dari mineral anorganik primer, sedangkan faktor yang paking penting adalah tingkatan bentuk hara yang tersedia bagi tanaman tingkatan tersebut tergantung pada banyak faktor di antaranya kelarutan zat hara, $\mathrm{Ph}$ tanah, kapasitas pertukaran kation, tekstur tanah, dan jumlah bahan organik yang ada. Selain unsur P, unsur K, yang terkandung dalam Abu Vulkanik juga berperan dalam meningkatkan pertambahan tinggi kopi liberika. Unsur $\mathrm{K}$ berperan sebagai aktivator enzim dalam reaksi fotosintesis, sehingga peningkatan unsur $\mathrm{K}$ akan meningkatkan laju fotosintesis dan fotosintat yang di hasilkan di manfaatkan untuk pertumbuhan tinggi tanaman. Unsur K berperan sebagai aktivator 
dari berbagai enzim yang ensesial dalam reaksi-reaksi metabolisme di antar proses fotosintesis $\mathrm{K}$ berperan secara langsung meningkatkan esimilasi $\mathrm{CO}_{2}$ dalam proses fotosinteses seta translokasi fotosintat.

\section{Diameter Batang}

Pertumbuhan diameter batang kopi liberika di pengaruhi oleh unsur kalium yang tersedia dalam Abu Vulkanik mempunyai unsur hara kalium yang sedang. Tersedianya unsur hara kalium maka pembentukan karbohidrat akan berjalan dengan baik dan translokai. Apabila suatu tanaman di tanam dalam keadaan linkungan yang baik serta semua unsur akan cukup tersedia kecuali satu unsur hara misalnya P yang terdapat dalam keadaan rendah maka pertemuan-pertemuan tanaman tersebut sebanding dengan jumlah unsur hara tersebut yang ditambahkan dalam tanah.Unsur kalium sangat berperan dalam meningkatkan diameter batang khususnya sebagai jaringn yang berhubungan antara akar dan daun pada proses transfirasi. Batang merupakan daerah akumulasi pertumbuhan tanaman khususnya pada tanaman yang lebih muda sehingga dengan adanya unsur hara dapat mendorong pertumbuhan vegetatif tanaman diantaranya pembentukan klorofil pada daun sehingga akan memacu laju fotosintesis. Semakin laju fotosintesis makan fotosintat yang di hasilkan akan memberikan ikuran pertambahan diameter batang yang besar.

\section{Luas Daun}

Pada luas daun Menunjukan bahwa pemberian Abu Vulkanik dan Dolomit terhadap pertumbuhan kopi liberika di lahan gambut memberikan perbedaan yang nyata terhadap luas daun kopi liberika. Pertambahan luas daun kopi liberika yang terluas adalah pemberian Abu vulkanik 250gr + Dolomit 250gr / Tanaman yang berbeda nyata semua perlakuan hal ini di duga unsur hara nitrogen dalam Abu Vulkanik di serap tanaman dengan baik sehingga menunjang pertumbuhan tanaman dan pembentukan asam amino dan pembentukan klorofil daun yang meyebabkan perkembangan permukaan daun yang lebih cepat.

Unsur nitrogen Andosol dalam tanah merupakan unsur hara ensensial yang kandungannya lebih tinggi di bandingkan dengan tanah lainnya. Dari data kandungan nitrogen total yang di analisis dari tanah andosol di beberapa tempat pulau jawa dan sumatra menunjukan bahwa kandungan nitrogen rata-rata tergolong sedang $(0,33 \%)$ dengan kisaran antara 0,11 sampai $0,76 \%$.

\section{KESIMPULAN DAN SARAN}

Berdasarkan hasil penelitian dan pembahasa maka dapat di simpulkan bahwa: 
1. Aplikasi Amelioran pupuk Abu Vulkanik dan Dolomit pada berbagai dosis, serta kombinasi dosis pada tanaman kopi menunjukan pengaruh yang tidak berbeda terhadap pertumbuhan vegetatip tanaman

2. Pemberian Amelioran pupuk Abu Vulkanik dan Dolomit pada berbagai dosis, serta kombinasi dosis pada tanaman kopi menunjukan pengaruh yang berbeda terhadap pertumbuhan Generip tanaman, dapat mempercepat pertumbuhan fase pertumbuhan gerneratip, mematahkan masa dormansi dan memacu inisiasi pembungaan.

3. Pemberian kobinasi Abu vulkanik 250gr + Dolomit 250gr dapat memacu pembungaan tanaman kopi dan menghasilkan jumlah dompolan bunga percabang dan jumlah bunga perdompolan yang lebih banyak dari perlakuan yang lain.

\section{Saran}

Disarankan untuk melakukan penelitian lebih lanjut tentang penggunaan Amelioran Abu Vulkanik dan dolomit dengan dosis yang lebih besar lagi untuk memperbaiki pertumbuhan dan produksi kopi liberika yang belum menghasilkan di lahan gambut.

\section{DAFTAR PUSTAKA}

Aak. 1988. Budidaya Tanaman Kopi. Kanisius, Yogyakarta.

Achmad, S. R. dan H. Hadi. 2015. Identifikasi sifat kimia abu vulkanik dan upaya pemulihan tanaman karet terdampak letusan gunung kelud (studi kasus: kebun ngrangkah pawon, jawa timur). Warta Perkaretan 34: 19-30.

Alviandy, R. Q., E. Ariani dan S. I. Saputra. 2016. Pemberian abu vulkanik terhadap pertumbuhan kelapa sawit (Elaeis guineensis Jacq.) di main nursery. Jurnal Online Mahasiswa Fakultas Pertanian 3: 1-11.

Andreita, R. R. 2011. Dampak debu vulkanik gunung sinabung terhadap perubahan sifat kimia tanah inceptisol. Skripsi, Universitas Sumatera Utara, Medan.

Aryanti, E., Yulita dan A. R. Annisava. 2016. Pemberian beberapa amelioran terhadap perubahan sifat kimia tanah gambut. Jurnal Agroteknologi 7: 19-26.

Azizah, R. 2017. Pertumbuhan kalus kopi liberika tungkal jambi(Coffea liberica var. liberica cv. Tungkal Jambi) dengan kombinasi 2,4-D dan kinetin secara in vitro. Skripsi, Universitas Jambi, Jambi.

Badan Pusat Statistik. 2018. Statistik Kopi Indonesia 2017. Badan Pusat Statistik, Jakarta.

Banjarnahor, B. J., Sarifuddin dan K. S. Lubis. 2018. Pengaruh pemberian beberapa amelioran terhadap sifat kimia tanah gambut dataran tinggi toba dan 
pengaruhnya terhadap pertumbuhan dan produksi tanaman padi (Oryza Sativa L.). Jurnal Agroteknologi Fakultas Pertanian Universitas Sumatera utara 6: 146-152.

Dinas Perkebunan Provinsi Jambi. 2018. Statistik Perkebunan Provinsi Jambi 2017. Dinas Perkebunan Provinsi Jambi, Jambi.

Kusumayati, N., E. E. Nurlaelih dan L. Setyobudi. 2015. Tingkat keberhasilan pembentukan buah tiga varietas tanaman tomat (Lycopersicon esculentum Mill.) pada lingkungan yang berbeda. Jurnal Produksi Tanaman 3: 683-688.

Maftu'ah, E., A. Maas, A. Syukur dan B. H. Purwanto. 2013. Efektivitas amelioran pada lahan gambut terdegradasi untuk meningkatkan pertumbuhan dan serapan NPK tanaman jagung manis (Zea mays L. var. saccharata). Jurnal Agronomi Indonesia 41: 16-23.

Nopiyanto, D. dan Sulhaswardi. 2014. Pengaruh penggunaan dosis dolomit dan pemberian amelioran KCa pada berbagai jenis media terhadap pertumbuhan mini cutting. Jurnal Dinamika Pertanian 29: 9-20.

Pamungkas, G., A. Sutandi dan B. Nugroho. 2017. Pengaruh trass dan kombinasi trass dengan abu merapi terhadap sifat kimia tanah serta pertumbuhan dan produksi biomassa tanaman padi (Oryza sativa) pada tanah gambut kumpeh, jambi. Buletin Tanah dan Lahan 1: 37-43.

Pujiwati, H., M. Ghulamahdi, S. Yahya, S. A. Aziz dan O. Haridjaja. 2015. Efisiensi pengapuran dengan amelioran air gambut memperbaiki adaptasi kedelai hitam (Glycine soja) terhadap cekaman $\mathrm{Al}$ dan Fe di lahan pasang surut, Seminar Nasional Lahan Suboptimal. Palembang.

Rachim, A. 1995. Penggunaan kation-kation polivalen dalam kaitannya dengan ketersediaan fosfat untuk meningkatkan produksi jagung pada tanah gambut. Disertasi, Institut Pertanian Bogor, Bogor.

Rahardjo, P. 2017. Berkebun Kopi. Penebar Swadaya, Jakarta.

Rudianto, G., D. Indradewa dan S. N. H. Utami. 2017. Pengaruh ketebalan abu volkan di atas permukaan tanah yang jatuh pada berbagai fase tumbuh terhadap pertumbuhan dan hasil jagung (Zea Mays L.). Jurnal Vegetalika 6: 1-11.

Sabiham, S., T. Prasetyo dan S. Dohong. 1995. Phenolic acids in Indonesian peat in Rieley and Page (Eds) Biodiversity and Sustainability of Tropical Peatland, 289292. Prosiding of the International Symposium on Biodiversity, Environmental Importance and Sustainability of Tropical Peats and Peatlands. Palangka Raya. Sajarwan, A. 2007. Kajian Karakteristik Gambut Tropika Yang Dipengaruhi Oleh Jarak Dari Sungai, Ketebalan Gambut, Dan Tipe Hutan Di Daerah Aliran Sungai Sebangun. Disertasi, Universitas Gajah Mada, Yogyakarta.

Salampak. 1999. Peningkatan produktivitas tanah gambut yang disawahkan dengan pemberian bahan amelioran tanah mineral berkadar besi tinggi. Disertasi, Institut Pertanian Bogor, Bogor. 
Sani. 2011. Pembuatan karbon aktif dari tanah gambut. Jurnal Teknik Kimia 5: 400-406.

Saragih, E. 1996. Pengendalian asam-asam fenolat meracun dengan penamabahan FeII pada tanah gambut dari Jambi, Sumatera. Tesis, Institut Pertanian Bogor, Bogor.

Soil Survey Staff. 2003. Soil Taxonomy. USDA, Washington.

Suastika, I. W., S. Sabiham dan D. A. S. 2006. Pengaruh pencampuran tanah mineral berpirit pada tanah gambut terhadap pertumbuhan dan hasil tanaman padi. Jurnal Ilmu-Ilmu Pertanian Indonesia 8: 99-109.

Subiksa, I. G. M., K. Nugroho, Sholeh dan I. P. G. W. Adhi. 1995. The effect of ameliorants on the chemical properties and productipity of peat soil, 321-325. Prosiding of the International Symposium on Biodiversity. Palangka Raya.

Zuraida. 2013. Penggunaan berbagai jenis bahan amelioran terhadap sifat kimia bahan tanah gambut hemik. Jurnal Floratek 8: 101-109. 